\title{
Designing Smooth Communication Environment for Telemedicine for General Practitioner
}

\section{$\operatorname{AUTHOR}(S)$ :}

Kuroda, Tomohiro; Hori, Kenta; Ando, Masahiko; Kawamura, Takashi; Takemura, Tadamasa; Yoshihara, Hiroyuki

\section{CITATION:}

Kuroda, Tomohiro ...[et al]. Designing Smooth Communication Environment for Telemedicine for General Practitioner. Lecture Notes in Computer Science 2012, 7258 : 253-263

\section{ISSUE DATE:}

2012

URL:

http://hdl.handle.net/2433/169716

\section{RIGHT:}

The final publication is available at www.springerlink.com; This is not the published version. Please cite only the published version.; この論文 は出版社版でありません。引用の際には出版社版をご確認ご利用くだ さい。 


\title{
Designing Smooth Communication Environment for Telemedicine for General Practitioner
}

\author{
Tomohiro Kuroda ${ }^{1}$, Kenta Hori ${ }^{2}$, Masahiko Ando ${ }^{3}$, Takashi Kawamura ${ }^{3}$, \\ Tadamasa Takemura ${ }^{1}$, and Hiroyuki Yoshihara ${ }^{1}$ \\ 1 Department of Medical Informatics, Kyoto University Hospital \\ Shogo-in Kawahara-cho 54, Sakyo-ku, Kyoto 606-8507, Japan \\ \{tomo, takemura, lob\}@kuhp.kyoto-u.ac.jp \\ 2 School of Radiological Technology, Gunma Prefectural College of Health Sciences \\ 323-1 Kamioki-machi, Maebashi, Gunma 371-0052, Japan \\ hori@gchs.ac.jp \\ 3 Kyoto University Health Service \\ Yoshida-Honmachi, Sakyo-ku, Kyoto 606-8501, Japan \\ \{kawax,mando\}@kuhp.kyoto-u.ac.jp
}

\begin{abstract}
Today's rapid advancement of the information and communication technologies enables us to perform telemedicine over the information networks. However, the realtime telemedicine is still not widely performed as a routine clinical activity. The authors developed a prototype multimedia communication system to support the realtime telemedicine and evaluated communication and technical barriers through protocol analysis. The results tell that ill synchronization and lack of non-verbal information may harm diagnostic process although the prototype enables general practitioners to diagnose a new patient from a remote site.
\end{abstract}

Keywords: Telemedicine, General practitioner, Realtime multimedia communication, Protocol analysis

\section{Introduction}

Today's rapid advancement of the information and communication technologies enables us to perform diagnostic process, named telemedicine, over the information networks among distant sites[2]. From technical point of view, telemedicine can be classified into two groups; the store-and-forward type telemedicine and the realtime telemedicine.

The store-and-forward type telemedicine is the approach to store obtained data once into certain storage and share the stored data among distant sites. This type of telemedicine, including telepathology[12] and teleradiology[1], is already technically and legally available and widely performed. Electronic health record (EHR) [3], which is to share electronic patient record (EPR) over the information 
networks among multiple clinical organizations, is also regarded as a variation of the store-and-forward type telemedicine.

The realtime telemedicine is the approach to transmit obtained data in realtime to enable a medical doctor to diagnose or to treat a patient over the information networks. Although innumerous trials are successfully performed, including the very early trial of telepsychiatry by Massachusetts General Hospital (MGH) back in 1968[6] and the transatlantic tele-robotic-surgery called "Operation Lindbergh" [4], the realtime telemedicine is still not widely performed as a routine clinical activity. In order to put the realtime telemedicine in practical use, we need to evaluate conventional realtime multimedia communication tools and to specify technical barriers of them under the most standard clinical process, which a general practitioner performs for a new patient.

The healthcare service section of schools and companies is one of the most common places to start clinical treatments. Recent mergers and relocation of schools and companies force the healthcare service section to provide their service, mainly pre-diagnosis for new patients, for remote sites.

The authors developed a realtime multimedia communication environment to realize telemedicine for newly opened campus of Kyoto University from its main campus. This paper discusses barriers and requirements of telemedicine under conventional communication tools through evaluation of the developed system.

\section{Designing and Prototyping Telemedicine System}

The common protocol to diagnose a new patient is to check the patient through interview, inspection, auscultation, and additional physiological / radiographic tests. Then, the doctor at the healthcare service division mainly provides consultation and guidance along the diagnosis, although the doctor sometimes introduces the patient in need for clinics and hospitals. Thus, the multimedia communication system to support telemedicine process of the healthcare service division needs to mediate conditions of the patient as well as messages from the doctors. Therefore, the communication support system should equips three channels, the standard TV-phone system for interview and inspection, another TV-phone system for detailed inspection and auscultation, and a shared memo pad for guidance. As a matter of course, existence of EPR to share physiological and radiographic test results helps diagnosis.

Fig.1,2 and Tab.1 shows configuration of the developed prototype[7]. The upper channel is a standard TV-phone system for interview and the lower channel is a shared memo pad. The middle channel dedicated to auscultation and detailed inspection equips an electric stethoscope, a standard inspection camera, a high definition still image camera, and a specially designed inspection camera for the oral cavity. The system utilizes DVTS [8] to transmit high-quality video and audio from the stethoscope with low latency, and FTP for the high definition still image. Fig. 3 shows the state transition of the middle channel. The doctor switches modes of the middle channel along the progress of the diagnostic process. 


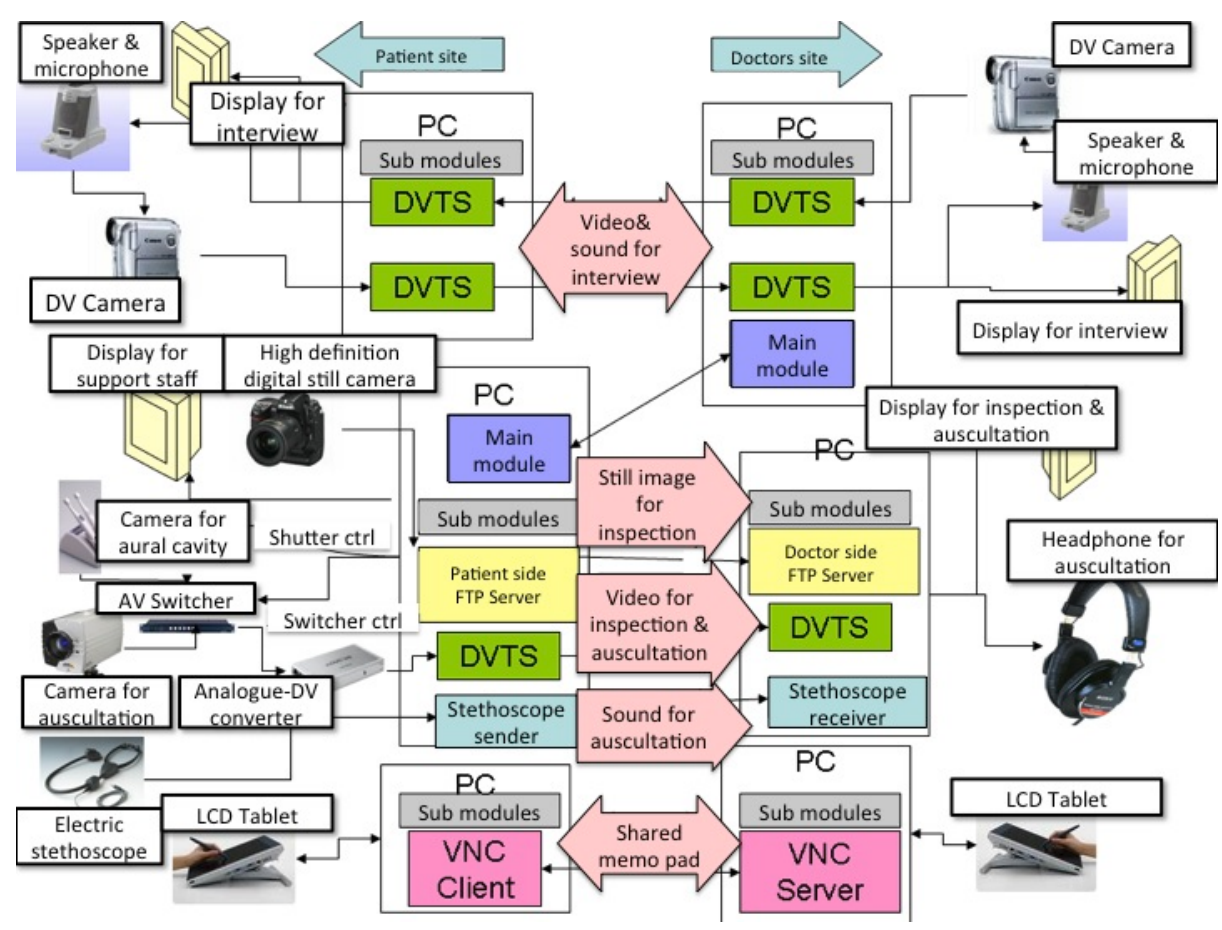

Fig. 1. The system configuration of the prototype

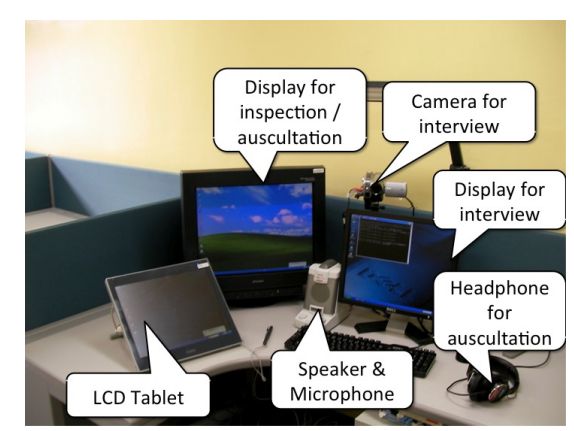

(a) Doctors site

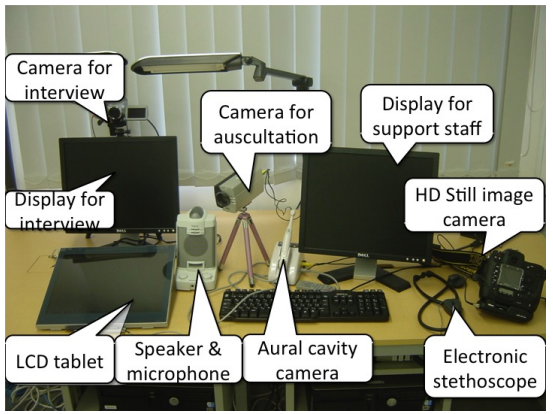

(b) Patient site

Fig. 2. The Interface of the prototype 
Table 1. The components of the prototype

\begin{tabular}{|l|l|}
\hline Component & Type \\
\hline \hline PC & DELL Optiplex 745 \\
\hline Display & DELL 19inch LCD Display \\
\hline Speaker Microphone & NEC Voice Point Mini \\
\hline DV camera & Panasonic NV-GS300-S \\
\hline High definition still camera & Nikon D2x+WT-2 \\
\hline Aural cavity camera & Morita Penscope (modified) \\
\hline Ausculation camera & AXIS 230 Mpeg2 Network Camera \\
\hline Electric Stethoscope & Cardionics E-scope \\
\hline LCD Tablet & Wacom DTI520 \\
\hline Headphone & Sony MDR-CD900ST \\
\hline
\end{tabular}

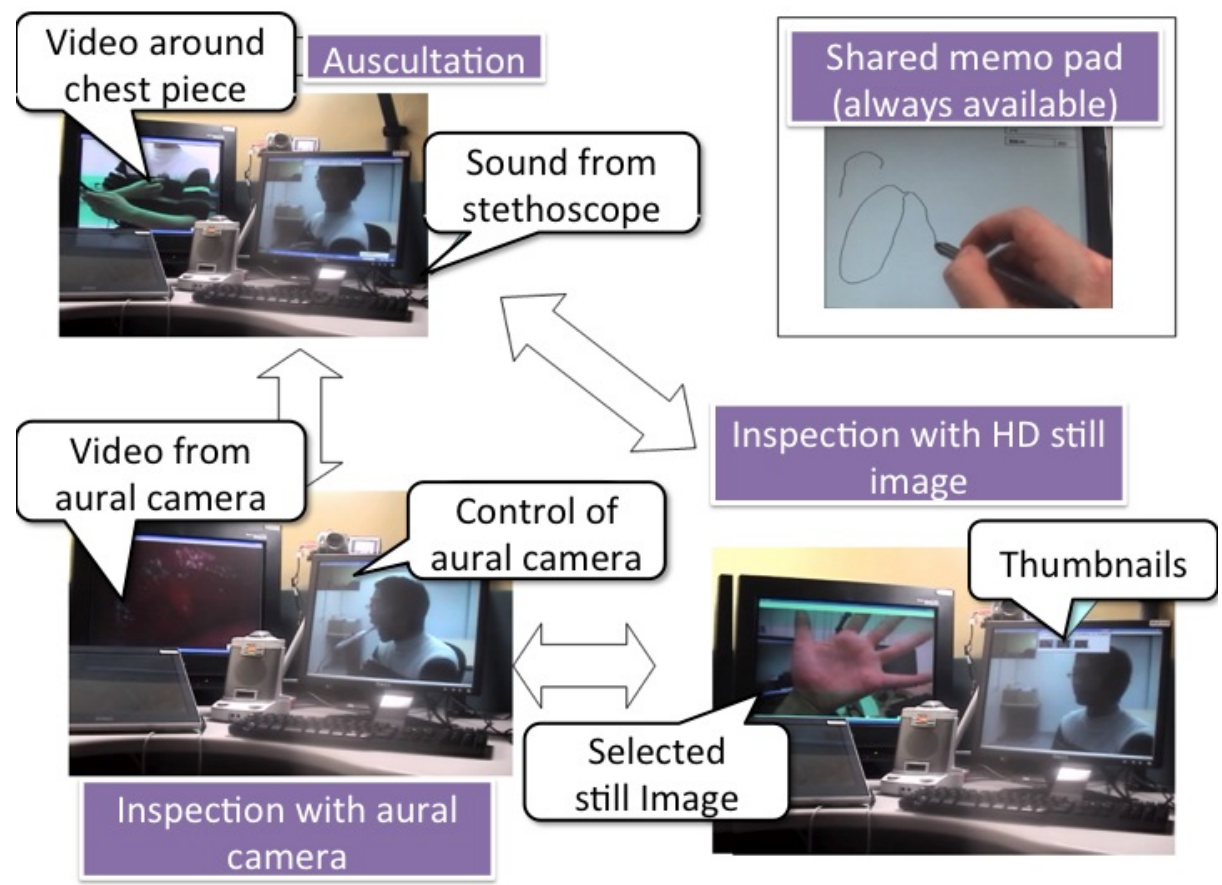

Fig. 3. The status transition diagram of the prototype 
The patient side terminal is installed to Katsura office of the Kyoto University Health Service where is ten kilometers away from the doctor side terminal at the main office of the Kyoto University Health Service. Two terminals are connected to a private VPN on the campus information network of Kyoto University named KUINS-3[11], whose backbone is $1 \mathrm{Gbps}$.

\section{$3 \quad$ Results and Discussions}

The initial introduction of the prototype clears that the most of the clinical staffs of the healthcare service division can handle the prototype after a few minutes of instruction. They can even restart whole system by themselves after some technical trouble. They confirmed that they can perform basic consultation using the prototype. However, the medical doctors claim that the prototype makes auscultation difficult due to its low sound quality and ill synchronization with video stream.

Along the results of initial introduction, the authors performed deeper analysis about problems on auscultation and difference between telemedicine and face-to-face consultation.

\subsection{Problems of Auscultation}

The auscultation is multimodal process. The medical doctor feels the movement of thorax through their own hand to know expiration and inspiration. The doctor also feels slight movements of the chest piece of the stethoscope and ignores the noise caused by the chest piece rubbing the thorax. Under telemedicine, the doctor cannot handle the chest piece by his own hand, and, consequently, cannot feel such movements. Although some foregoing researches try to introduce maserslave type robots into telemedicine, to ask a supporter next to the patient to place the chest piecec is more realistic technically and legally. Thus, we need to utilize visual key instead of haptic key.

Synchronization between multiple media is one of the most important factors for successful communication under multimodal telecommunication. The authors evaluated how the synchronization error effects on the auscultation. Two medical doctors performed pseudo tele-auscultation under several conditions. Fig.4 and 5 shows the scene of the pseudo tele-auscultation. Here, one doctor plays patient and supporter, that is, he places the stethoscope on his own chest and breathes as another doctor asks. Tab.2 shows the conditions and the results. In the table, the two-tuple number in each cell gives evaluation of two doctors. Tab.3 shows the evaluation scores. The result clearly shows that the error of synchronization may harm auscultation. Especially, the auscultation of breath sound becomes impossible when video and sound differs $10 \%$ of the respiratory cycle. The medical doctors claims that even 100 milli-second differences may cause medical doctors to misunderstand expiration and inspiration. 


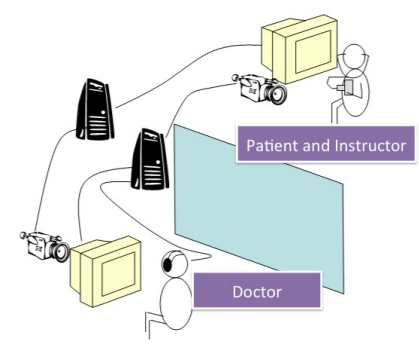

Fig. 4. Sketch of pseudo tele-auscultation

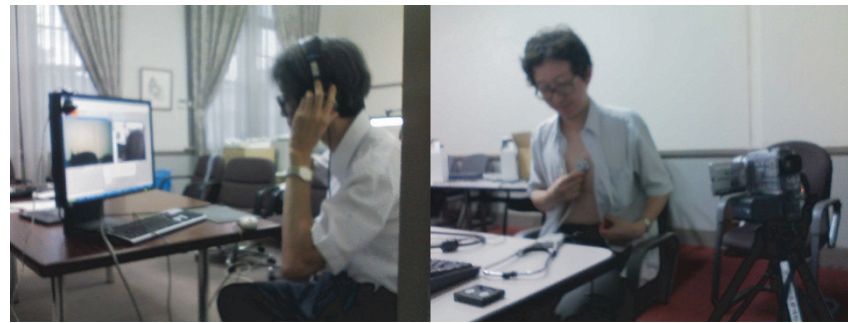

(a) Remote (doctor) site (b) patient/supporter site

Fig. 5. Snapshot of pseudo tele-auscultation

Table 2. Result of pseudo tele-auscultation

\begin{tabular}{|l||c|c|c|}
\hline \multicolumn{1}{|c|}{ Delay between video and audio } & $100 \mathrm{~ms}$ & $200 \mathrm{~ms}$ & $300 \mathrm{~ms}$ \\
\hline Status of sound & & & \\
\hline \hline Heart sound (normal $6080 / \mathrm{min}$ ) & $5: 5$ & $4: 3$ & $3: 3$ \\
\hline Breath sound (slow $1215 / \mathrm{min}$ ) & $4: 5$ & $5: 4$ & $2: 2$ \\
\hline Breath sound (fast $3040 / \mathrm{min}$ ) & $1: 1$ & $1: 1$ \\
\hline
\end{tabular}

Table 3. Evaluation score

\begin{tabular}{|c|l|}
\hline Score & Evaluation \\
\hline \hline 5 & Doesn't notice \\
\hline 4 & Notice but doesn't matter \\
\hline 3 & Troublesome but doesn't affect diagnosis \\
\hline 2 & May affect diagnosis \\
\hline 1 & Impossible to diagnose \\
\hline
\end{tabular}




\subsection{Comparing Telemedicine and Face-to-Face Consultation}

For more detailed evaluation, the authors tried to expose the difference of telemedicine and conventional face-to-face consultation using protocol analysis[9].

Medical doctors are asked to perform pseudo consultation under the following scenario under telemedicine and face-to-face condition.

- Scenario 1: Diagnose a patient with suspected pneumonia by a respiratory specialist introduced by a general practitioner (GP).

- GP at the patient's site diagnoses the patient.

- GP introduces specialist at the remote site.

- The specialist inspects the patient.

- The specialist auscultates the patient.

- The specialist explains the diagnostic result

- Sceario 2: Diagnose a patient with hand eczema when no doctor is at the patients site.

- A nurse introduces a doctor at the remote site.

- The doctor interviews the patient.

- The doctor inspects the patient.

- The doctor explains diagnosis and tells to visit dermatologist.

Whole session videotaped and analyzed. After the analysis the authors and medical doctors had a retrospective report session. Some typical results are shown in Tab.4 and 5.

Although the clinical process itself didn't change, the result clearly shows that telemedicine requires more time to perform clinical process.

One main reason is inevitable actions to perform telemedicine, denoted "to do it remotely" in the tables. The clinical staffs at the patient's site need to tell the condition of the patient to the remote site, and the clinical staffs need to take pictures or videos to transmit still image or some additional data to the remote site. As all the data exchanged under telemedicine is need to be digitized[2], these additional tasks are inevitable for detailed process.

Another reason is the ineffectiveness of the prototype, denoted "system manipulation" in the tables. The clinical staffs sometimes have some trouble to find correct switches to start up required subsystems, and the doctors need to concentrate drawing a picture due to slippery surface of the tablet. Such problems can be solved by tunings and trainings.

The other problem is the communication difficulties over TV-phone. Under conventional consultation, the doctor just needs to take a paper out from his desk to tell the patient that he start to explain the diagnostic result. But under telemedicine, the doctor needs to speak out what he will do and ask the patient to look onto the LCD tablet. The clinical staffs need to speak out to know how the process is going at another site. As a matter of course, experience to perform telemedicine may dramatically decrease such additional tasks. Actually, the clinical staffs required fewer checkups at the end of the session. However, as patients are always new, the messages or orders for the patients won't be reduced. Additional technologies to share the atmosphere or non-verbal communication such as share AR technology may be required to smoothen the communication. 
Table 4. Test result of scenario 1

\begin{tabular}{|c|c|c|c|c|c|c|c|c|c|}
\hline \multirow{2}{*}{\multicolumn{2}{|c|}{ Clinical process }} & \multicolumn{3}{|l|}{ Result } & \multicolumn{5}{|c|}{ Reasons of time difference } \\
\hline & & \multirow{2}{*}{$\begin{array}{l}\text { Tele- } \\
\text { medicine } \\
34\end{array}$} & \multirow{3}{*}{$\begin{array}{l}\text { Face to } \\
\text { face } \\
18\end{array}$} & \multirow{3}{*}{$\begin{array}{r}\begin{array}{r}\text { Time } \\
\text { diff. }\end{array} \\
29\end{array}$} & \multirow{3}{*}{$\begin{array}{l}\text { System } \\
\text { manipulation }\end{array}$} & \multirow{3}{*}{$\begin{array}{l}\text { System } \\
\text { trouble }\end{array}$} & $\begin{array}{l}\text { To do it } \\
\text { remotely }\end{array}$ & \multirow{3}{*}{$\begin{array}{l}\text { Difference } \\
\text { of process }\end{array}$} & \multirow{2}{*}{ Others } \\
\hline & Dr. with patient & & & & & & & & \\
\hline & Dr. at remote & 13 & & & & & & & \\
\hline \multirow{3}{*}{$\begin{array}{l}\text { Prepare } \\
\text { inspection }\end{array}$} & Staff & 6 & & 6 & 6 & & & & \\
\hline & Dr. at remote & 2 & 3 & -1 & & & & & -1 \\
\hline & Patient & 4 & 3 & 1 & & & & & 1 \\
\hline \multicolumn{2}{|l|}{ Inspection } & 24 & 6 & 18 & 4 & $14 \dagger$ & & & \\
\hline \multicolumn{2}{|c|}{ After inspection process } & 3 & & 3 & 3 & & & & \\
\hline Prepare & Dr. at remote & 2 & 3 & -1 & & & & & -1 \\
\hline auscultation & Patient & 14 & 11 & 3 & & & & & 3 \\
\hline \multicolumn{2}{|l|}{ Auscultation } & 76 & 60 & 16 & & & 10 & $6+$ & \\
\hline \multicolumn{2}{|l|}{ Explanation } & 11 & & 11 & 11 & & & & \\
\hline \multicolumn{2}{|l|}{ Drawing } & 5 & 3 & 2 & 2 & & & & \\
\hline \multicolumn{2}{|l|}{ Explanation } & 45 & 31 & 14 & 14 & & & & \\
\hline \multicolumn{2}{|l|}{ Total } & 239 & 138 & 101 & 40 & 14 & 39 & 6 & 2 \\
\hline
\end{tabular}

$\uparrow$ Due to restarting system after system halt.

$¥$ Doctor auscultated two more points in telemedicine. 
Table 5. Test result of scenario 2

\begin{tabular}{|c|c|c|c|c|c|c|c|c|}
\hline \multirow[b]{2}{*}{ Clinical process } & \multicolumn{3}{|l|}{ Result } & \multicolumn{5}{|c|}{ Reasons of time difference } \\
\hline & Telemedicine & $\begin{array}{l}\text { Face to } \\
\text { face }\end{array}$ & $\begin{array}{l}\text { Time } \\
\text { difference }\end{array}$ & $\begin{array}{l}\text { System } \\
\text { manipulation }\end{array}$ & $\begin{array}{l}\text { System } \\
\text { trouble }\end{array}$ & $\begin{array}{l}\text { To do it } \\
\text { remotely }\end{array}$ & $\begin{array}{l}\text { Difference } \\
\text { of process }\end{array}$ & Others $\dagger$ \\
\hline Explain patient condition & 22 & & 22 & & & 22 & & \\
\hline Interview & 12 & 8 & 4 & 4 & & & & \\
\hline Prepare inspection & 10 & & 10 & & & 10 & & \\
\hline Photo taking & 17 & & 17 & & & 17 & & \\
\hline Photo quality check & 9 & & 9 & & & 9 & & \\
\hline System manipulation & 6 & & 6 & 6 & & & & \\
\hline Inspection & 8 & 11 & -3 & & & & & -3 \\
\hline Interview & 12 & 17 & -5 & & & & & -5 \\
\hline Inspection & 13 & 5 & 8 & & & & & 8 \\
\hline Interview & 9 & 5 & 4 & & & & & 4 \\
\hline Inspection & 4 & 3 & 1 & & & & & 1 \\
\hline Interview & 3 & 22 & -19 & & & & & -19 \\
\hline Inspection & 6 & 9 & -3 & & & & & -3 \\
\hline Explanation & 19 & 28 & -9 & & & & & $-9 \ddagger$ \\
\hline Total & 190 & 108 & 42 & 10 & & 48 & & -26 \\
\hline
\end{tabular}

※unit: (second)

$\dagger$ Difference caused by personality of doctors, so it may counted

$\mp$ In face-to-face process, the doctor explains diagnosis to patient 


\section{Conclusions}

This paper developed a multimedia communication system to support realtime telemedicine and evaluated communication problems under telemedicine. The results tell that the conventional multimedia communication system may support providing clinical services at the same level as conventional face-to-face consultation. However, the evaluation tells that the erroneous synchronization and the lack of multimodal communication may harm telemedicine. As the requirements for communication quality is quite dependent on clinical process and purpose of each media, a specially designed application-level QoS (Quality of Service) control communication toolkit, as the one Mori et al[5] proposed, may be indispensable. For smooth telemedicine, the system needs to provide certain alternative methods to transmit atmosphere or non-verbal information, as the one Suenaga et al[10] proposed.

\section{Acknowledgements}

The authors would like to thank our brillient students, Mr. Takashi Nakai and Mr. Takashi Tsukasa, for their precious support to develop and introduce the prototype into real clinical environment. The authors also thank Morita MFG. Corp. who developed the aural cavity camera. The authors also thank Dr. Kazuo Nakazawa and Dr. Ryo Haraguchi of National Cerebral and Cardiovascular Center for their advice to develop LCD tablet-based shared memo pad. At last, the authors would like to thank all the staffs of the Kyoto University Health Service for their support for all the evaluations. This paper partly funded by Kyoto University Rector's Funding Program and Initiatives for Attractive Education in Graduate Schools program of JSPS.

\section{References}

1. Goldberg, M.A.: Teleradiology and telemedicine. Radiolo. Clin. North Am. 34(3), 647-65 (1996)

2. Hori, K.: Information support for telesurgery. In: Kumar, S., Marescaux, J. (eds.) Telesurg., pp. 101-11. Springer-Verlag (2008)

3. Li, J.S., Zhou, T.S., Chu, K., Araki, K., Yoshihara, H.: Design and development of an international clinical data exchange system: the international layer function of the dolphin project. J. Am. Med. Inform. Assoc. 18(5), 683-9 (2011)

4. Marescaux, J., Leroy, J., Gagne, M., Rubio, F., Mutter, D., Vix, M., Butner, S.E., Smith, M.K.: Transatlantic robot-assisted telesurgery. Nature 413, 379-80 (2001)

5. Mori, M., Tsukasa, T., Hori, K., Kuroda, T., Yoshihara, H.: Network QoS control system application for telemedicine. Trans. Jap. Soc. Med. Biolog. Eng. 42(4), 140-6 (2004)

6. Murphy, R.L.H., Bird, K.T.: Telediagnosis: a new community health resource: observations on the feasibility of telediagnosis based on 1000 patient transactions. Am. J. Pub. Health 64, 113-9 (1974) 
7. Nakai, T., Tsukasa, T., Hori, K., Takemura, T., Kuroda, T., Ando, M., Kawamura, T., Yoshihara, H.: Application of real-time multimedica communication technology into health care service. Jap. J. Telemed. Telecare 4(1), 35-40 (2008), Japanese

8. Ogawa, A., Kobayashi, K., Sugiura, K., Nakamura, O., Murai, J.: Design and implementation of DV based video over RTP. In: Packet Video Workshop (2000)

9. Rubin, J.: Handbook of Usability Testing: How to Plan, Desifn, and Cunducting Effective Tests. John Wiley \& Sons (1994)

10. SUenaga, T., Kuroda, T., Manabe, Y., Chihara, K.: A tele-instruction system for real-time telemedicine. In: Proc. Comp. Aid. Radiol. Surg. pp. 498-503 (2000)

11. Takakura, H., Ebara, Y., Miyazaki, S., Sawada, A., Nakamura, M., Okabe, Y.: Structure and security of secure gigabit network system, KUINS-III. Trans. IEICE J86-B(8), 1494-1501 (2003), Japanese

12. Weinstein, R.S., Bhattacharyya, A.K., Graham, A.R., Davis, J.R.: Telepathology: a ten-year progeress report. Hum. Pathol. 28(1), 1-7 (1997) 